\title{
In Memoriam: Jozef Ijsewijn
}

Bien connu de tous les latinistes, le professeur Jozef Ijsewijn est décédé le 27 novembre 1998 à la suite d'une pénible et ineroxable maladie. Celle-ci s'était déclarée peu avant le dernier congrès de l'Association internationale pour la promotion des études néolatines (Avila, août 1997). C'était la première fois en 25 ans que celui qui en avait été le fondateur ne participerait pas au congrès trisannuel de cette Association.

Étudiant en philologie classique, Jozef Ijsewijn s'était initialement spécialisé en papyrologie, domaine en lequel il obtint son doctorat en 1959. Son intérêt pour la culture classique, dans son ouverture la plus large, ne diminua pas pour autant. Fasciné, comme Pétrarque, par la pure sonorité du latin, il serait bientôt un excellent latiniste.

Nullement passéiste et parfaitement conscient que le latin ne pourrait jamais redevenir la lingua franca qu'elle avait été en Occident, il était par ailleurs profondément convaincu de la nécessité pour la culture européenne de maintenir vivante la mémoire de cette latinité, qui fut une de ses sources essentielles. C'est en cet esprit que, dès 1966, Jozef Ijsewijn allait, à Louvain, créer le Seminarium Philologiae Humanisticae, bientôt suivi de la réorganisation de la revue Humanistica Lovaniensia, qui, sous son impulsion et son égide, deviendra, de par le monde, la référence obligée des études néolatines.

C'est à Louvain également qu'en 1970, dans le cadre de l'Institut d'études médiévales, il organisera un colloque international ayant pour thème "The Late Middle Ages and the Dawn of Humanism." Ce colloque donnera lieu à un premier Congrès des études néolatines, lors duquel Jozef Ijsewijn prit l'initiative de fonder la Societas Internationalis Studiis Neolatinis Provehendis, dont il deviendrait l'animateur et la cheville ouvrière, après en avoir été le concepteur. Jusqu'à Bari (1994), il fut de tous les congrès de cette Association, y participant toujours très activement et continuant d'y jouer, à différents titres, un rôle de tout premier plan. 
C'est encore à Jozef Ijsewijn que l'on doit le célèbre Companion to Neo-Latin Studies, ouvrage fondamental acclamé de par le monde entier et qui restera sans doute son grand oeuvre. Publié en 1977, le Companion connut en 1990 une première réédition retravaillée et largement augmentée. Ce premier volume fut suivi d'un second tome, paru tout récemment.

De par son rayonnement, son activité infatiguable et sa présence habituelle aux congrès de la S.I.S.L.P., qu'il animait de son dynamisme, Jozef Ijsewijn était une personnalité de tout premier plan. Comme tel, il était respecté par une vaste communauté de chercheurs qui garderont de lui le souvenir d'un homme d'une parfaite intégrité intellectuelle, ouvert au dialogue, très rigoureux et exigeant en ce qui concerne les études et la recherche. L'humanisme, pour lui, n'était ni un vain mot ni seulement un champ d'études...

LOUIS VALCKE, Université de Sherbrooke 